Jurnal Kesehatan Karya Husada, Vol 9 No 2 Tahun 2021

PISSN 2337649X/EISSN 2655-8874

Emmelia Ratnawati "Latihan "Salam Trendi" Terhadap Kekuatan Otot dan Kecepatan Berjalan Lansia

Paska Stroke di Kota Depok" (hal 112-121)

Received

Revisied

Acceptep

10 Desember 2020

20 Februari 2021

16 Juni 2021

\title{
LATIHAN "SALAM TRENDI" TERHADAP KEKUATAN OTOT DAN KECEPATAN BERJALAN LANSIA PASKA STROKE DI KOTA DEPOK
}

\author{
Emmelia Ratnawati ${ }^{1}$, Astuti Yuni Nursasi ${ }^{2}$, Sukihananto ${ }^{3}$ \\ 1. Sekolah Tinggi Ilmu Kesehatan Panti Rapih, Yogyakarta 55584, Indonesia \\ 2. Program Studi Magister, Fakultas Ilmu Keperawatan, Universitas Indonesia \\ 3. Fakultas Ilmu Keperawatan, Universitas Indonesia, Depok 16424, Indonesia \\ E-mail: emmelia_ratnawati@stikespantirapih.ac.id
}

\begin{abstract}
ABSTRAK
Stroke pada lansia mengakibatkan keterbatasan kemandirian. Latihan Salam Trendi terdiri dari latihan nafas dalam, stretching, dan rentang pergerakan sendi merupakan salah satu latihan untuk mengurangi keterbatasan. Latihan dilakukan di rumah dan bersifat individual $2 x / m i n g g u$ selama 4 minggu. Penelitian ini bertujuan mengidentifikasi pengaruh latihan "Salam Trendi" terhadap kekuatan otot dan kecepatan berjalan lansia paska stroke di Kota Depok. Penelitian menggunakan desain Quasi Eksperimen pre dan post test design. Jumlah sampel 44 responden yang terdiri dari kelompok perlakuan dan kelompok kontrol yang dipilih dengan tehnik consecutive sampling. Evaluasi penelitian dilakukan pada hari pertama dan minggu keempat. Hasil penelitian menunjukkan bahwa kekuatan otot lengan $(p=0.042)$ dan kaki $(p=0.005)$; kecepatan berjalan $(p=0.002)$ berubah secara signifikan setelah diberikan latihan. Hal ini berarti latihan Salam Trendi berpengaruh terhadap peningkatan kekuatan otot dan kecepatan berjalan lansia paska stroke. Penelitian ini merekomendasikan perlunya latihan ini sebagai salah satu intervensi perawat dalam asuhan keperawatan lansia paska stroke di komunitas.
\end{abstract}

Kata kunci: Stroke; lansia; latihan Salam Trendi; kekuatan otot, kecepatan berjalan.

\begin{abstract}
Stroke in the elderly resulted in limited autonomy. Exercise Salam Trendy consists of deep breathing exercises, stretching, and range of motion is one exercise to reduce limitations. Exercises done at home and individual $2 x /$ week for 4 weeks. This study aimed to identify the effects of exercise "Salam Trendy" against muscle strength and walking speed of elderly post-stroke in Depok. Quasi-Experimental research design using pre and post test design. Total sample of 44 respondents consisting of the treatment group and the control group were selected with consecutive sampling technique. Evaluation studies conducted on the first and fourth week. The results showed that the arm muscle strength $(p=0.042)$ and legs $(p=$ $0.005)$; walking speed $(p=0.002)$ increased significantly after being given a workout. This means that the exercise "Salam Trendy " affect the increase in muscle strength and walking speed. The study recommends the need for this exercise as one of the interventions of nurse elderly post-stroke in the community.
\end{abstract}

Keyword: Stroke; the elderly; exercise Salam Trendy; muscle strength, walking speed. 
Emmelia Ratnawati "Latihan "Salam Trendi" Terhadap Kekuatan Otot dan Kecepatan Berjalan Lansia Paska Stroke di Kota Depok" (hal 112-121)

\section{PENDAHULUAN}

Lansia dengan stroke merupakan kelompok rentan. Kerentanan mencakup sakit kronis dan kecacatan yang berdampak pada ketidakmampuan, kualitas hidup, dan pembiayaan kesehatan (Allender, Rector, dan Warner, 2014). Lansia dengan stroke mengalami perubahan fisiologis dan keterbatasan fungsional yang berakibat keterbatasan kemandirian.

Hasil Riskesdas (2018) menyatakan prevalensi stroke di Indonesia berdasarkan diagnosis dokter meningkat dari $0.7 \%$ (2013) menjadi $1.09 \%$. Prevalensi stroke di Jawa Barat mencapai $1.1 \%$. Profil usia terbanyak penderita stroke adalah usia 55-64 tahun: $3.3 \%$, usia $65-74$ tahun: $4.61 \%$, dan usia lebih dari 75 tahun: 6.7\%. Pola penyakit stroke di rawat inap rumah sakit usia 45-> 75tahun: 6.17\%, di rawat jalan: $4.88 \%$ (Profil Kesehatan Kota Depok, 2017).

Konsekuensi fungsional pada kardiovaskuler dan mekanisme barorefleks menurunkan kecepatan aliran darah ke serebral yang dapat menyebabkan stroke (Miller, 2012).
Salah satu masalah akibat stroke adalah gangguan motorik. Ligamentum menjadi kaku dan terjadi penurunan kelenturan sehingga mengurangi gerakan persendian. Immobilisasi dapat menyebabkan kehilangan kekuatan otot. Penurunan kemampuan muskuloskeletal menurunkan aktivitas fisik dan latihan yang berpengaruh pada kemampuan melakukan aktivitas sehari-hari (Smeltzer dan Bare, 2008). Latihan pada lansia paska stroke seringkali hanya dilakukan beberapa kali setelah lansia pulang dari rumah sakit. Menurut Perry dan Potter (2009), rehabilitasi kemampuan mobilitas difokuskan pada range of motion, cara berjalan, latihan dan toleransi terhadap aktivitas, dan sikap tubuh.

Latihan Salam Trendi merupakan salah satu alternatif latihan yang dapat dilakukan oleh lansia paska stroke. Latihan ini terdiri dari tiga latihan yaitu nafas dalam, stretching, dan rentang pergerakan sendi. Latihan Salam Trendi merupakan prosedur yang sederhana sehingga dapat dilakukan oleh lansia paska stroke di rumah. Tujuan latihan Salam Trendi 
Jurnal Kesehatan Karya Husada, Vol 9 No 2 Tahun 2021

PISSN 2337649X/EISSN 2655-8874

Emmelia Ratnawati "Latihan "Salam Trendi" Terhadap Kekuatan Otot dan Kecepatan Berjalan Lansia

Paska Stroke di Kota Depok" (hal 112-121)

adalah relaksasi otot dan mengoptimalkan fungsi motorik menggunakan kombinasi latihan untuk meningkatkan kerja jantung, kekuatan otot, dan meningkatkan kecepatan berjalan.

Penelitian tentang range of motion lebih banyak dilakukan di rumah sakit dan panti. Penelitian tentang kombinasi nafas dalam, stretching, dan rentang pergerakan sendi pernah dilakukan Erwanto (2014) mengukur kemampuan rehabilitasi pada kelompok lansia paska stroke di Cimanggis.

Berdasarkan uraian di atas menurut peneliti perlu dilakukan penelitian tentang pengaruh nafas dalam, stretching, dan rentang pergerakan sendi (Salam Trendi) terhadap kekuatan otot dan kecepatan berjalan lansia paska stroke di Kota Depok.

\section{METODE PENELITIAN}

Penelitian ini menggunakan design quasi eksperimen dengan rancangan non randomized control group pretest posttest. Besar sampel yang diambil dengan consecutive sampling dengan total sampling 44 lansia paska stroke. Kelompok perlakuan $(n=22)$ adalah lansia paska stroke yang bertempat tinggal bertempat tinggal di wilayah Kecamatan Sukmajaya,diberi latihan Salam Trendi 15-20 menit, diulang sekali dengan interval istirahat selama selama 3 menit, 2 kali per minggu, selama 4 minggu. Kelompok kontrol $(n=22)$ adalah lansia paska stroke di wilayah Kecamatan Pancoran Mas. Penelitian ini dilaksanakan pada $6 \mathrm{Mei}$ - 8 Juni 2015. Pengumpulan data dilakukan dengan menggunakan kuesioner uji kekuatan otot dan uji kecepatan berjalan 10 meter.

\section{HASIL PENELITIAN}

Analisis univariat menggambarkan karakteristik dari 44 responden diantaranya rerata usia responden adalah 64.86 tahun dalam rentang 6074 tahun. Mayoritas jenis kelamin adalah laki-laki (56.8\%). Mayoritas frekuensi stroke adalah serangan pertama (88.6\%). Kekuatan otot lengan pada kelompok perlakuan meningkat dari 3.00 menjadi 3.18 setelah intervensi sedangkan kelompok kontrol tidak mengalami peningkatan. Kekuatan otot kaki pada kelompok perlakuan meningkat dari 3.95 menjadi 4.27 dan kelompok 
Jurnal Kesehatan Karya Husada, Vol 9 No 2 Tahun 2021

PISSN 2337649X/EISSN 2655-8874

Emmelia Ratnawati "Latihan "Salam Trendi" Terhadap Kekuatan Otot dan Kecepatan Berjalan Lansia Paska Stroke di Kota Depok" (hal 112-121)

kontrol juga meningkat dari 4.23

menjadi 4.32. Kecepatan berjalan pada

kelompok kontrol meningkat dari 0.4

menjadi 0.52 dan pada kelompok

kontrol juga meningkat dari 0.45

menjadi 0.46. Setelah dilakukan

latihan Salam Trendi terdapat

perbedaan signifikan pada kekuatan

otot lengan $(\mathrm{p}=0.042 ; \quad \alpha=0.05)$,

kekuatan otot kaki $(\mathrm{p}=0.005 ; \alpha=0.05)$,

kecepatan berjalan $(\mathrm{p}=0.02 ; \alpha=0.05)$.

Tabel 1. Perubahan kekuatan otot

lansia paska stroke di Kota Depok

\begin{tabular}{|c|c|c|c|c|c|c|c|}
\hline \multirow{2}{*}{$\begin{array}{l}\text { Kek } \\
\text { uata }\end{array}$} & Kelo & \multicolumn{2}{|c|}{$\mathrm{n}$} & \multirow{2}{*}{$\begin{array}{l}\mathrm{M} \\
\mathrm{e}\end{array}$} & \multirow{4}{*}{$\begin{array}{l}\text { S } \\
\text { D }\end{array}$} & \multirow{4}{*}{$\begin{array}{l}\mathrm{S} \\
\mathrm{E}\end{array}$} & \multirow{4}{*}{$\begin{array}{c}\text { pValu } \\
\text { e }\end{array}$} \\
\hline & mpo & & & & & & \\
\hline $\mathrm{n}$ & $\mathrm{k}$ & & & $\mathrm{a}$ & & & \\
\hline otot & & & & $\mathrm{n}$ & & & \\
\hline Len & Perla & 2 & Seb & 3. & 1 & 0 . & 0.000 \\
\hline \multirow[t]{20}{*}{ gan } & kuan & 2 & elu & 0 & . & 30 & \\
\hline & & & $\mathrm{m}$ & 0 & 4 & & \\
\hline & & & & & 1 & & \\
\hline & & & Ses & 3. & 1 & 0. & \\
\hline & & & uda & 1 & . & 29 & \\
\hline & & & $\mathrm{h}$ & 8 & 3 & & \\
\hline & & & & & 7 & & \\
\hline & & & Seli & 0. & 0 & 0. & 0.042 \\
\hline & & & $\operatorname{sih}$ & 1 & . & 08 & \\
\hline & & & & 8 & 3 & & \\
\hline & & & & & 9 & & \\
\hline & Kont & 2 & Seb & 3. & 1 & 0. & \\
\hline & rol & 2 & elu & 4 & . & 31 & \\
\hline & & & $\mathrm{m}$ & 1 & 4 & & \\
\hline & & & & & 7 & & \\
\hline & & & Ses & 3. & 1 & 0. & \\
\hline & & & uda & 4 & . & 31 & \\
\hline & & & $\mathrm{h}$ & 1 & 4 & & \\
\hline & & & & & 7 & & \\
\hline & & & Seli & 0 & 0 & 0 & \\
\hline
\end{tabular}

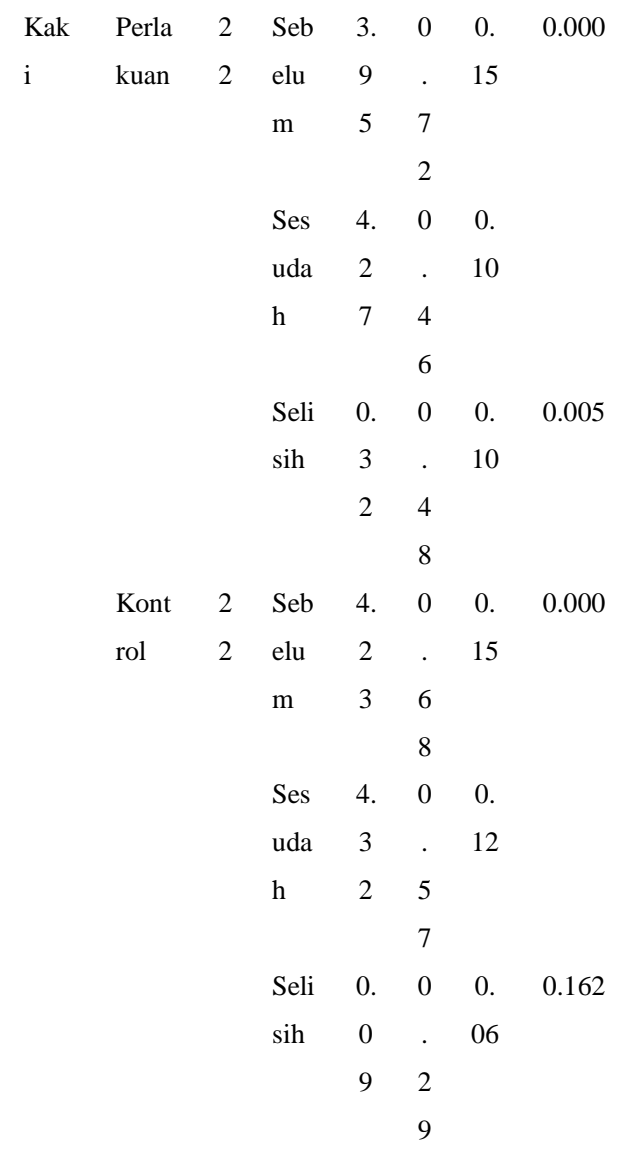

Tabel 2. Perubahan kecepatan berjalan lansia paska stroke di Kota Depok

\begin{tabular}{|c|c|c|c|c|c|c|}
\hline $\begin{array}{l}\text { Kecepat } \\
\text { an } \\
\text { Berjalan }\end{array}$ & & $\mathrm{n}$ & $\begin{array}{l}\text { Mea } \\
\mathrm{n}\end{array}$ & SD & $\mathrm{SE}$ & $\begin{array}{l}\mathrm{p} \\
\text { Valu } \\
\mathrm{e}\end{array}$ \\
\hline Perlakua & Sebelu & 2 & 0.40 & 0.2 & 0.05 & 0.00 \\
\hline \multirow[t]{3}{*}{$\mathrm{n}$} & $\mathrm{m}$ & 2 & & 9 & & 2 \\
\hline & Sesuda & & 0.52 & 0.3 & 0.07 & \\
\hline & $\mathrm{h}$ & & & 5 & & \\
\hline
\end{tabular}


Emmelia Ratnawati "Latihan "Salam Trendi" Terhadap Kekuatan Otot dan Kecepatan Berjalan Lansia Paska Stroke di Kota Depok" (hal 112-121)

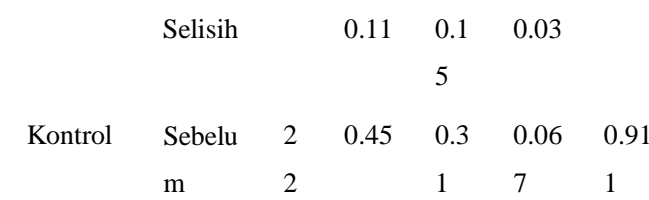

\begin{tabular}{|c|c|c|}
\hline Sesuda & 0.47 & 0.3 \\
\hline $\mathrm{h}$ & & 1 \\
\hline \multirow[t]{2}{*}{ Selisih } & 0.00 & 0.8 \\
\hline & 2 & 9 \\
\hline
\end{tabular}

\section{PEMBAHASAN}

Rerata usia responden penelitian ini adalah 63.23 tahun pada kelompok perlakuan dan 66.50 tahun pada kelompok kontrol. Hal ini sesuai data BPS (2020) bahwa di Indonesia didominasi oleh lansia berusia 60-69 tahun dengan jumlah yang mencapai 64,29\%. Hal ini dikuatkan oleh penelitian Limansyah (2014) usia lansia paska stroke antara 63.74 66.40. Usia ini juga sesuai data Riskesdas (2013) yang menyebutkan bahwa presentase profil lansia stroke usia 55-64 tahun sebesar 3.3\%, usia 65-74 tahun sebesar 4.16\%. Usia harapan hidup di Indonesia pada tahun 2020 adalah 71.47 tahun sehingga proporsi lansia paska stroke sangat mungkin pada usia tersebut. Perubahan fungsi fisiologis kardiovaskuler karena bertambahnya usia mempengaruhi kecepatan aliran darah ke otak. Insiden terjadinya stroke berlipat sejak usia 55 tahun dan dua pertiga kejadian stroke terjadi pada usia lebih dari 65 tahun (Guzman et al, 2012). Stroke pada usia lanjut diperkirakan dipengaruhi oleh masalah aterosklerosis yang banyak diderita lansia. Smeltzer dan Bare (2008) menyebutkan bahwa penyebab utama stroke adalah trombosis serebral yang diakibatkan arterisklerosis dan pelambatan sirkulasi serebral.

Haghighi et al (2009) menyebutkan bahwa ada hubungan positif antara usia dan pengetahuan tentang stroke yaitu semakin tinggi usia dan tingkat pendidikan, pengetahuan tentang stroke dan perawatannya juga meningkat. Proses rehabilitasi merupakan suatu proses belajar yang melibatkan memori jangka panjang tentang kemampuan motorik sehingga memudahkan untuk memiliki kemampuan motorik yang telah dipelajari terdahulu (Mudie dan Matyas,2000). Hal tersebut menguatkan bahwa lansia mempunyai kemampuan memori jangka panjang yang menurun sehingga berdampak pada waktu pemulihan paska stroke. 
Emmelia Ratnawati "Latihan "Salam Trendi" Terhadap Kekuatan Otot dan Kecepatan Berjalan Lansia Paska Stroke di Kota Depok" (hal 112-121)

Hasil penelitian ini menunjukkan bahwa mayoritas jenis kelamin lansia paska stroke adalah laki-laki. Hasil penelitian Bergstrome et al (2011) menyebutkan bahwa $67 \%$ dari partisipan adalah laki-laki. Hal ini dikuatkan oleh Black dan Hawk (2009) yang menyatakan bahwa risiko stroke lebih besar pada laki-laki daripada perempuan. Faktor risiko yang menyebabkan laki-laki menderita stroke adalah stres, hipertensi, merokok, alkohol, diet yang kurang baik, kurangnya latihan fisik, dan penyakit lainnya. Penelitian Cahyati (2011) di Tasikmalaya menyebutkan jenis kelamin tidak perbedaan dalam pemulihan kemampuan motorik pasien stroke.

Frekuensi serangan stroke pada penelitian ini mayoritas terjadi pada serangan pertama. Hal ini menunjukkan bahwa kejadian stroke memang baru muncul setelah usia lebih dari 60 tahun, dan serangan pertama merupakan kondisi yang baik dalam proses rehabilitasi. Gordon (2002) menyebutkan bahwa perbaikan kelainan neurologis sebagian berlangsung pada 6 bulan pertama rehabilitasi. Stroke ulang memiliki mortalitas dan kecacatan yang lebih tinggi dibanding stroke pertama karena pada stroke ulang, jaringan otak belum sepenuhnya pulih dari serangan pertama sehingga berdampak lebih berat (Bethesda Stroke Center, 2007). Cahyati (2011) menyebutkan bahwa frekuensi stroke pada penelitiannya tidak mempengaruhi peningkatan kemampuan motorik pasien stroke karena sebagian besar responden mendapat penanganan yang cepat setelah serangan pertama.

Hasil penelitian ini menunjukkan kekuatan otot meningkat setelah diberikan latihan Salam Trendi. Penelitian Astrid (2008) menunjukkan bahwa setelah diberikan latihan ROM dengan frekuensi 4 kali sehari selama 7 hari kekuatan otot meningkat secara signifikan. Hal ini dikuatkan oleh penelitian Erwanto (2014) latihan NADA ROMS yang diberikan setiap minggu selama 3 bulan memberikan pengaruh terhadap kekuatan otot lansia paska stroke.

Peningkatan kekuatan otot dalam penelitian ini dapat disebabkan adanya latihan dengan menggerakkan tangan kaki dengan Gerakan fleksi, ekstensi, hiperekstensi, abduksi, adduksi, rotasi, 
Emmelia Ratnawati "Latihan "Salam Trendi" Terhadap Kekuatan Otot dan Kecepatan Berjalan Lansia Paska Stroke di Kota Depok" (hal 112-121)

sirkumduksi, eversi, inversi, pronasi, dan supinasi. Setiap Gerakan dilakukan sampai terdapatnya sedikit tahanan, sistematis dan urutannya sama pada sesi latihan.

Kecepatan berjalan pada lansia paska stroke sebelum diberikan latihan pada penelitian ini adalah 0.4 meter/detik, sedangkan setelah diberikan latihan adalah 0.52 meter/detik. Latihan fisik secara teratur dan terbimbing dapat meningkatkan kemampuan berjalan khususnya kecepatan berjalan. Hal ini sejalan dengan penelitian Olawais et al (2011) yang menyebutkan bahwa latihan yang diberikan selama 12 minggu mempunyai efek terhadap fungsi berjalan kelompok paska stroke. Braden et al (2012) melaporkan kecepatan berjalan pada laki-laki adalah 0.54 meter/detik dan 0.40 meter/detik pada perempuan, serta setiap penurunan kecepatan 0.10 meter/detik mengindikasikan buruknya status kesehatan.

Berjalan merupakan kemampuan lokomotor yang digunakan untuk memindahkan tubuh dari satu tempat ke tempat yang lain (Carr dan Shepherd, 2010). Kemampuan berjalan klien stroke dipengaruhi oleh kelemahan pada satu sisi, control tubuh yang menurun serta ketidakstabilan pola berjalan. Keterbatasan berjalan pada klien stroke terjadi pada fase menapak dan fase mengayun kaki. Keterbatasan pola berjalan juga disebabkan adanya kontraksi dalam dan luar yang terjadi karena kurangnya pergerakan sendi secara penuh. Hal ini diperkuat dengan penelitian Tulandi, Kundre, dan Silolonga (2014) tentang Range of Motion pasif untuk Gerakan fleksi, hiperekstensi, abduksi, dan adduksi pada panggul menunjukkan ada pengaruh terhadap luas gerak sendi panggul.

\section{SIMPULAN DAN SARAN}

\section{Simpulan}

1. Terdapat perubahan bermakna pada kekuatan otot lansia paska stroke sebelum dan sesudah diberikan latihan Salam Trendi.

2. Terdapat perubahan bermakna pada kecepatan berjalan lansia paska stroke sebelum dan setelah diberikan latihan Salam Trendi. 
Jurnal Kesehatan Karya Husada, Vol 9 No 2 Tahun 2021

PISSN 2337649X/EISSN 2655-8874

Emmelia Ratnawati "Latihan "Salam Trendi" Terhadap Kekuatan Otot dan Kecepatan Berjalan Lansia

Paska Stroke di Kota Depok" (hal 112-121)

\section{Saran}

1. Bagi perawat

Melatih dan melibatkan kader serta keluarga cara merawat lansia paska stroke terutama aktivitas fisik di rumah

2. Bagi peneliti selanjutnya

Disarankan kepada peneliti selanjutnya terkait dukungan keluarga dalam latihan Salam Trendi sehingga kemampuan lansia paska stroke lebih optimal.

\section{DAFTAR PUSTAKA}

Allender, Judith Ann; Cherie Rector; Kristine D.W. (2014). Community and public health nursing: promoting the public's health. 8th ed. Philadelphia: Lippincott Williams \& Wilkins

Astrid, M., Nurachmah, E., Budiharto. (2008). Pengaruh Latihan Range of Motion (ROM) Terhadap Kekuatan Otot, Luas Gerak Sendi dan Kemampuan Fungsional Pasien Stroke di RS Sint Carolus Jakarta. Tesis. Jakarta: Tidak dipublikasikan

Bergstorm A., Eriksson G., Koch L., Tham K. (2011). Combined life satisfaction of persons with stroke and their caregivers: associations with caregiver burden and the impact of stroke. Health And Quality of Life Outcomes, 9:1.

Bethesda Stroke Centre. (2007). Faktor resiko stroke usia muda. http://www.strokebethesda.com

Black, J.M., \&Hawks, J.H. (2009). Medical surgical nursing: Clinical management for positive outcomes (8thed). St Louise: Elsevier. Inc.

Badan Pusat Statistik (2020). Statistik Penduduk Lansia 2020. Jakarta: Badan Pusat Statistik

Braden H., et al. (2012). Gait Speed Is Limited but Improves Over the Course of Acute Care Physical Therapy. Journal of Geriatric Physical Therapy. Volume 35. Number 3. July-September 2012. DOI:

10.1519/JPT.0b013e31828baale Cahyati Y., Nurachmah E., Hastono S.P. (2011). Perbandingan Latihan ROM Unilateral dan Latihan ROM Bilateral Terhadap kekuatan Otot Pasien Hemiparese Akibat Stroke Iskemik Di RSUD Kota Tasikmalaya dan RSUD Kab 
Jurnal Kesehatan Karya Husada, Vol 9 No 2 Tahun 2021

PISSN 2337649X/EISSN 2655-8874

Emmelia Ratnawati "Latihan "Salam Trendi" Terhadap Kekuatan Otot dan Kecepatan Berjalan Lansia Paska Stroke di Kota Depok" (hal 112-121)

Ciamis. Tesis. Jakarta. Tidak dipublikasikan

Carr, J.H, Shepherd, R.B. (2010). Neurological Rehabilitation: Optimizing Motor Performance. Sydney: Churchill Livingstone

Dinas Kesehatan Kota Depok. (2017).

Profil Kesehatan Pemerintah Daerah Kota Depok 2016. Depok: Dinas Kesehatan Kota Depok

Erwanto, R., Sahar J., Widyatuti.

(2014). Pengaruh Intervensi Keperawatan Komunitas "Nafas Dalam, Rentang Gerak Sendi dan Peregangan” Terhadap Peningkatan Kemampuan Rehabilitasi Pada Kelompok lansia Paska Stroke di Kelurahan Curug, Kecamatan Cimanggis. KIA. Jakarta: Tidak dipublikasikan

Guzman, Allan, et al. (2012). Selfconcept, disposition, and Resilience of Poststroke Filipino Elderly with Residual paralysis. Educational Gerontology, 38: 429 $-442$

Gordon, NF, et al (2004). Physical Activity and Exercise Recommendations for Stroke Survivors: An American Heart
Assosiation Scientific Statement From Council on Clinical Cardiology, Subcommittee on Exercise, Cardiac Rehabilitation, and Prevention; the Council on Cardiovaskuler Nursing; the Council on Nutrition, Physical Activity, and metabolism; and the Stroke Council. Stroke: 35: 12301240. www.stroke.ahajournals.org Haghighi, Afshin. B., et al. (2010). Knowledge and attitude towards stroke risk factors, warning symptoms and treatment in an Iranian population. Journal Medical Principles and Practice: 19: 468 - 472. DOI: $10.1159 / 000320306$

Kementerian Kesehatan RI. (2013). Hasil Riskesdas 2013. Jakarta: Kementerian Kesehatan RI

Kementerian Kesehatan RI. (2018). Hasil Riskesdas 2018. Jakarta: Kementerian Kesehatan RI

Miller, Carol, A. (2012). Nursing for Wellness in Older Adults. Sixth Edition. Philadelphia: Lippincott Williams \& Wilkin

Mudie M.H., Mtyas T.A. (2000). Can simultameous bilateral movement involve the undamaged 
Jurnal Kesehatan Karya Husada, Vol 9 No 2 Tahun 2021

PISSN 2337649X/EISSN 2655-8874

Emmelia Ratnawati "Latihan "Salam Trendi" Terhadap Kekuatan Otot dan Kecepatan Berjalan Lansia Paska Stroke di Kota Depok" (hal 112-121)

hemisphere in reconstruction of

neural networks damaged by

stroke? Disability and

Rehabilitation, 22(1/2): 23-37

Olawais OA., et al (2011). Exercise training improves walking function in an African group of stroke survivors: a randomized controlled trial. Journal Clinical Rehabilitation. Volume 25. Hal 442-450.

DOI:

$10.1177 / 0269215510389199$

Potter P.A.; Perry A.G. (2009).

Fundamentals of Nursing. 7th

Edition. St. Louise: Mosby

Elsevier

Smeltzer SC \& Bare G. (2008).

Brunner \& Suddarth: Textbook of medical surgical nursing. Philadelphia: Lippincott Williams \& Wilkins 